\title{
Binocularity and visual search
}

\author{
JEREMY M. WOLFE and SUSAN L. FRANZEL \\ Massachusetts Institute of Technology, Cambridge, Massachusetts
}

\begin{abstract}
This paper describes a series of visual search experiments for targets defined by their binocular characteristics. In searches for targets defined by binocular rivalry among fused distractors, or vice versa, the rivalrous items do not "pop out" (reaction time [RT] increases with number of distractors). Binocular luster, a variety of rivalry, is an exception. Luster, an important property of visible surfaces, behaves like a basic feature or "texton" (RT independent of the number of nonlustrous distractors). Searches for targets defined exclusively by eye-of-origin information are virtually impossible. Subjects respond randomly, suggesting that purely monocular information is not available for visual search. Searches for cyclopean (but nonstereoscopic) features are easy, with RTs independent of set size, suggesting that some purely binocular information is available for visual search.
\end{abstract}

There has been considerable recent interest in our ability to search for one type of item among a number of other items presented simultaneously (e.g., Johnston \& Dark, 1986; Julesz, 1984; Treisman \& Gelade, 1980). In some cases, all the items seem to be examined at once and visual search appears to be performed in parallel across the visual field. For example, a green item can be located in a field of red items very rapidly regardless of the number of red items. It simply "'pops out." By contrast, in other situations, reaction times (RTs) increase as a linear function of set size, suggesting that the visual system can deal with only one or few items at a time. In such tasks, a serial item-by-item search of successive locations in the visual field seems to be required. Thus, the time required to find a $\mathrm{T}$ among Ls increases as the number of items in the field increases. The T does not pop out. ${ }^{1}$

Treisman's (Treisman \& Gelade, 1980; Treisman \& Schmidt, 1982) "feature integration" model is one effort to explain why some searches seem serial whereas others are parallel. Treisman argues that basic features of the visual input (e.g., motion, orientation, color, and size) can be extracted in parallel, whereas searches for more complex properties (e.g., conjunctions of simple features) require that the "spotlight of attention" move from item to item until the target is found. Subsequent work forces some modification in this model. Nakayama and Silverman (1986) and Steinman (1987) showed that some conjunctions involving stereoscopic depth or motion could be found in parallel (e.g., stereo and motion, stereo and color). Pashler (1987) argued that subjects could examine clumps of items when searching for conjunctions, particularly with small set sizes. Egeth, Virzi, and Garbart

This research was supported by the Whitaker Health Sciences Fund and BRSG funds from the N.I.H. We thank IBM for the loan of YODA color boards, Allan Doyle for programming assistance, and Kyle Cave, Anne Treisman, Charles Eriksen, Harold Pashler, and an anonymous reviewer for helpful discussions and suggestions. The senior author's mailing address is Department of Brain and Cognitive Sciences, E10137, Massachusetts Institute of Technology, Cambridge, MA 02139.
(1984) found that subjects could ignore all items of one color and limit a serial search to the items of the same color as the target. Finally, when our subjects have performed searches for conjunctions of color and form, the slopes of the resulting $\mathrm{RT} \times$ set size functions have been too shallow to be consistent with a serial self-terminating search (Wolfe, Cave, \& Franzel, 1988). Nevertheless, with some modifications, Treisman's basic model can be made to handle these findings while preserving the model's basic form (Wolfe et al., 1988). In its broad outlines, this model is similar to Julesz's $(1981,1984,1986$; Julesz \& Bergen, 1983) “texton'” model with its distinction between preattentive (parallel) and attentive (serial) processing.

Given this type of model, it is reasonable to ask what the basic features are and where, in the flow of visual processing, the transition from parallel to serial processing occurs. The experiments reported here addressed those questions within the context of binocular vision. It is known that stereoscopic depth is a basic feature in the sense that it supports parallel visual search (Nakayama \& Silverman, 1986). Our visual search experiments involved other stimuli, defined by their binocular properties, that had not been employed in previous work. These include items that produce binocular rivalry, items that have cyclopean (but not stereoscopic) features, and items that are defined by eye-of-origin information. Our results showed that detecting instances of rivalry (or fusion) requires serial search except when rivalry is perceived as "luster." Searches for lustrous targets seem to be parallel, suggesting that luster qualifies as a basic feature or texton. Cyclopean (nonstereoscopic) features can be found by parallel search. Finally, the search for items on the basis of eye-of-origin information alone is generally impossible.

\section{GENERAL METHODS}

All of the experiments used methods similar to those of Treisman and her co-workers. On each trial, an array of items is presented to the subject. It either does or does not contain the designated tar- 
get item. Subjects respond by pressing one key if they detect the target and another if they do not. RTs are measured from the time of stimulus onset. The items are visible until the subject responds.

Stimuli were presented on the color monitor of a modified "SubRoc 3-D" video game driven by an IBM-PC with IBM YODA color graphics boards. Stimuli were presented at $60 \mathrm{~Hz}$, interlaced. Monocular presentation was accomplished by presenting the odd raster lines to one eye and the even lines to the other by means of a rotating shutter arrangement yoked to the video refresh signal. The resulting images had a noticeable, but unobtrusive, 30$\mathrm{Hz}$ flicker.

Two types of displays were used-one for small set sizes $(2,4$, and 8 items) and one for large set sizes (8, 16, and 32 items). For the small set sizes, subjects viewed a $11.4^{\circ}$-diam ring binocularly to maintain vergence. When the subject pressed a key, a set of 2 , 4 , or 8 items appeared within the ring. Each item was $4^{\circ}$ from the fixation point and was, at maximum, $1.6^{\circ}$ square. There were eight possible stimulus locations evenly spaced around the circle. Even spacing was maintained for all set sizes. Thus, for set size 2 , the two items were constrained to be on opposite sides of the circle. For set size 4, the items were constrained to form the corners of a square or diamond.

For the large-set-size experiments, the outer circle was replaced by a square, $11.3^{\circ}$ on a side. Items were a maximum of $0.85^{\circ}$ square and were presented in a randomly chosen subset of a $6 \times 6$ array of possible locations. These 36 locations were evenly spaced $0.85^{\circ}$ apart, with a small, random displacement in the $x$ and $y$ dimensions added to break up the regularity of the grid.

In both versions of the experiment, a binocular fixation point was placed in the center of the display. Experimental sessions were selfpaced, with each trial initiated by the subject with a buttonpress. Responses were made by another buttonpress. Overall percentage of target trials was specified by the experimenter. The presence or absence of a target on any given trial was randomized. Set size and target location (if any) were also randomized. The order of stimuli was different for each subject. Feedback was provided by the computer after each trial.

Subjects were shown the target and distractor items and told to respond as quickly as possible while minimizing errors. Two hundred or 300 trials were run per subject, depending on the experiment. These were preceded by $20-30$ practice trials.

Subjects were recruited from the MIT community and paid for their participation. All subjects read and signed an informed consent form. All subjects had normal stereo acuity, as assessed by the Randot test, and all wore their best optical correction (if any) during the experiment. Experimental sessions (often involving blocks of trials from two experiments) took about $1 \mathrm{~h}$. Many subjects were tested repeatedly, and thus, after the first session, were not strictly naive. The authors also served as subjects in many of the experiments. The authors' RTs tended to be somewhat faster than average, but the pattern of results did not differ from those obtained from naive subjects.

\section{PART 1: SEARCHING FOR RIVALRY}

When the two eyes are presented with different stimuli at the same location in visual space, the viewer will see a competition between the two stimuli. At any one moment, only one of the two stimuli will be perceived at any particular location. This distinctive perception is known as binocular rivalry (Breese, 1909; Walker, 1978). In the first set of experiments, we asked if rivalry could be detected in parallel in the presence of a set of fused distractors-stimuli identical in both eyes. Rivalry comes in several forms (e.g., color, form, and luster). Therefore, several variations of the basic rivalry experiment were conducted.

\section{Experiment 1: Form Rivalry}

\section{Method}

A sample of the stimuli for Experiment 1 is shown in Figure 1. Figure 1a shows a stimulus presented to the left eye in the 8-item condition. At each location, there is a $1.6^{\circ}$ square patch of vertical or horizontal lines (high contrast, square-wave grating 3.1 cycles per degree, cpd). Figure $1 \mathrm{~b}$ shows the corresponding right eye stimulus. At seven locations, the orientation of the patch is identical to that in the left eye. At the eighth (indicated by a small circle NOT presented to the subject), the orientation is orthogonal and will produce rivalry. The subject pressed one key if rivalry was detected and another if it was not.

Twelve subjects were tested. The subjects saw 20 practice trials to familiarize themselves with the appearance of rivalry and the use of the response buttons. The experiment consisted of 300 trials, $75 \%$ of which contained a rivalry target; the remainder held only fused distractors.

\section{Results}

The task is quite simple. Error rates were under $5 \%$ for 11 of 12 subjects. When the data were analyzed, RTs less than $200 \mathrm{msec}$ or greater than 3,000 msec were discarded as motor errors. RTs for incorrect answers were not included in average RTs. Average RTs for correct responses are shown in Figure 2. Lines fitted to the data are least squares estimates of the best fit and were used to derive estimates of the average increase in RT with each additional distractor. RTs for both target and blank trials increase as set size increases. The slope is $\mathbf{2 6}$ msec per item for target trials and $36 \mathrm{msec}$ for blank trials.

An analysis of variance (ANOVA) was performed on the RT data. The main effects of set size and trial type (target present or absent) were highly significant ( $p<.001$ for both). The interaction between set size and trial type failed to reach significance $[F(2,22)=2.776$, $p=.08]$. Eight of 12 subjects had steeper slopes for tar-

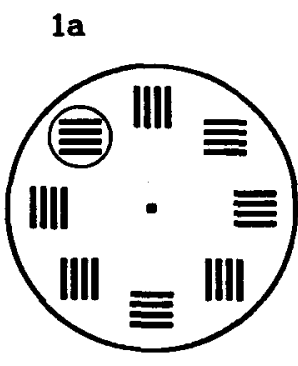

Left Eye

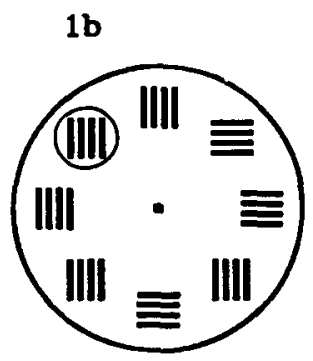

Right Eye
Figure 1. Sample stimulus with a target for Experiment 1. A random assortment of vertical and horizontal gratings is presented to each eye alone. For a set size of 8 , the orientation of a grating in the left eye is the same as that in the right at seven locations. At the eighth location (marked by a small circle not shown to the subject), the orientations are orthogonal, producing binocular rivalry. On blank trials, left and right eyes would see the same orientations at all eight locations. 


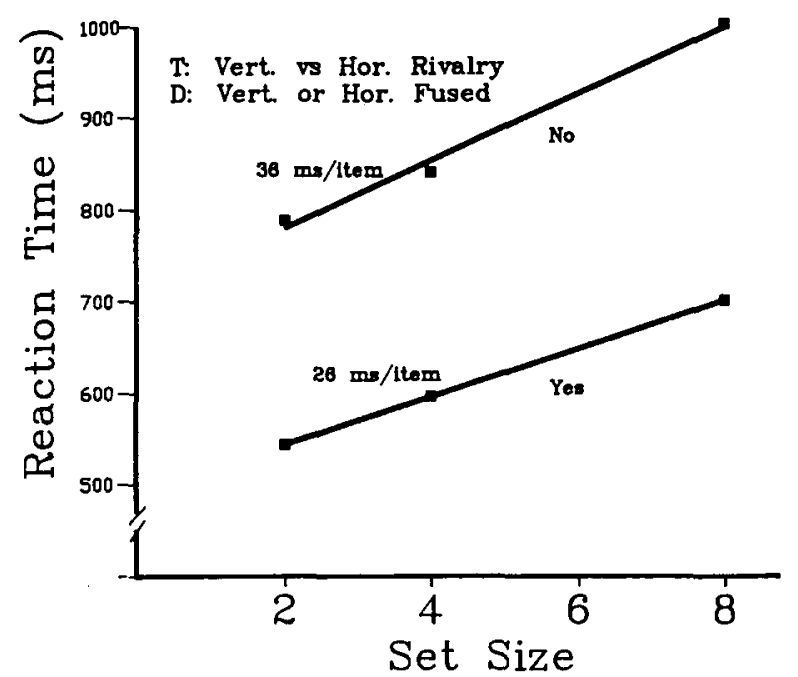

Figure 2. Searches for form rivalry targets among fused distractors. Average data for Experiment 1. In this and subsequent graphs, the line labejed "Yes" shows average RTs for target trials. "No" designates blank trials. In Experiment 1, rivalry targets do not pop out.

get trials than for blank trials (binomial $p=.12$ ). The average slope for blank trials ir. significantly greater than that for targets, but only barely $[t(11)=1.8, p<.05]$.

\section{Discussion}

The increase in RT with set size is consistent with the hypothesis that detection of rivalry targets cannot be done in parallel. The search seems to involve a process with a limited capacity. The search does not appear to be strictly serial and self-terminating. Serial self-terminating searches should yield a 2:1 ratio between the slopes for blank and target trials. Here the slope ratios vary considerably across subjects. Although statistical analysis is somewhat unclear on the significance of the difference between the slopes of target and blank trials, it is obvious that the slope ratios are not consistently in a $2: 1$ ratio. To test the 2:1 ratio hypothesis, the target-trial slope was doubled and subtracted from the blank-trial slope for each subject. Averaged over subjects, this difference should be zero. In fact, it is significantly smaller than zero $[t(11)=1.9, p<.05]$. Pashler $(1987)$ also failed to find evidence for serial, self-terminating search with small set sizes. We examine larger set sizes in Experiment 4.

Rivalry has characteristics that make it somewhat different from other visual search stimuli. It is possible that one monocular stimulus could be completely suppressed, leaving no "target" to be detected. This "unitary rivalry" generally occurs only if stimuli are less than $1^{\circ}$ in diameter (see, e.g., Blake, Westendorf, \& Overton, 1980; Kaufman, 1963). If each of our items were undergoing such unitary rivalry, then there might be no obvious target at stimulus onset. The rivalry target would be seen only after alternation began. The items in our stimuli are larger than $1^{\circ}$. Introspectively, the rivalry targets appeared to be composites of vertical and horizontal and were easily discriminable from the fused distractors. Moreover, even if unitary rivalry did occur, there is no reason to assume that it would have a greater effect on set sizes of 8 than of 2 .

\section{Experiment 2: Spacing Effects}

By evenly spacing items, we introduced a systematic relationship between the spacing of items and the set size. Spacing between items decreased as the set size increased. If the presence of a fused neighbor made it more difficult to detect the rivalry target, then this spacing factor could account for the increase in RT with set size. We examined this possibility in a control experiment. Set size was held constant at 2 items. On $50 \%$ of the trials, one of these was a rivalry target. The subjects reported on the presence or absence of rivalry. On each trial, one item was randomly placed at one of the eight possible stimulus locations. The second item was placed randomly at one of the seven remaining locations. Seven subjects were run, with 350 trials per subject.

The results were analyzed in terms of the spacing between the items. Average RTs for target and blank trials are shown in Table 1. Standard deviations average $275 \mathrm{msec}$ across all conditions. There is no obvious effect of spacing. Certainly, smaller spacings do not seem to produce reliably longer RTs than longer spacings. An ANOVA reveals a significant effect of trial type $[F(1,6)=$ $28.4, p=.002]$, but no main effect of spacing $[F(6,36)=$ $1.5, p=.202]$ and no interaction of spacing and trial type $[F(6,36)=1.9, p=.107]$.

With a spacing effect ruled out, Experiment 1 indicates that rivalry targets do not pop out in visual search.

\section{Experiment 3: Color Rivalry}

Different colors presented dichoptically will rival (Helmholtz, 1909/1924, pp. 503-505), and such rivalry is at least somewhat independent of form rivalry (e.g., Hastorf \& Myro, 1959). Experiment 3 tested the possibility that searches for an example of color rivalry might

Table 1

Average Response Times for Rivalry Search With a Set Size of 2 as Spacing Between the Two Items Varies

\begin{tabular}{ccc}
\hline & \multicolumn{2}{c}{ Average RT } \\
\cline { 2 - 3 } Spacing & Target Trials & Blank Trials \\
\hline 0 & 564 & 660 \\
1 & 558 & 631 \\
2 & 565 & 614 \\
3 & 584 & 621 \\
4 & 553 & 592 \\
5 & 570 & 616 \\
6 & 595 & 620 \\
\hline
\end{tabular}

Note-Spacing, the number of intervening blank positions, is defined as the clockwise spacing from target item to distractor item on target trials. For blank trials, spacings 0 and 6,1 and 5, and 2 and 4 are identical. 
be conducted in parallel even if searches for an example of form rivalry required serial search.

\section{Method}

The methods were identical to those in Experiment 1. Only the items changed. Instead of vertical versus horizontal rivalry targets, red versus green rivalry targets were used with binocular red or green spots as distractors. Eight subjects were tested.

\section{Results}

Figure 3 shows average RTs and best-fit lines for the color rivalry experiment. As in Experiment 1, RT increased with set size. Slopes were $18 \mathrm{msec}$ per item for target trials and $35 \mathrm{msec}$ per item for blank trials. Error rates were less than $5 \%$ for 6 of the 8 subjects and less than $10 \%$ for the remaining 2 subjects. An ANOVA showed a significant effect of set size $[F(2,14)=23.93$, $p<.001]$ but, curiously, no significant effect of trial type $[F(1,7)=3.50, p=.104]$. The interaction of trial type and set size was, likewise, not significant $[F(2,14)=2.55$, $p=.114]$.

\section{Discussion}

Color rivalry targets, like form rivalry targets, do not pop out. Although the average slopes are in the 2:1 relationship predicted by self-terminating search, that relationship is not statistically reliable. In fact, the blank-trial slopes are not significantly greater than the target-trial slopes $[t(7)=1.56, p>.05]$. The data from individual subjects clearly show that subjects adopt very different strategies in responding to blank trials. Some subjects seem to employ a very slow checking procedure that yields slopes as high as $70 \mathrm{msec} /$ item. The standard deviation of the slopes for blank trials is 25 , whereas that for the target trials is 10. This great variability in the blank-trial slopes makes inferences about serial self-terminating searches impossible. It remains clear, however, that

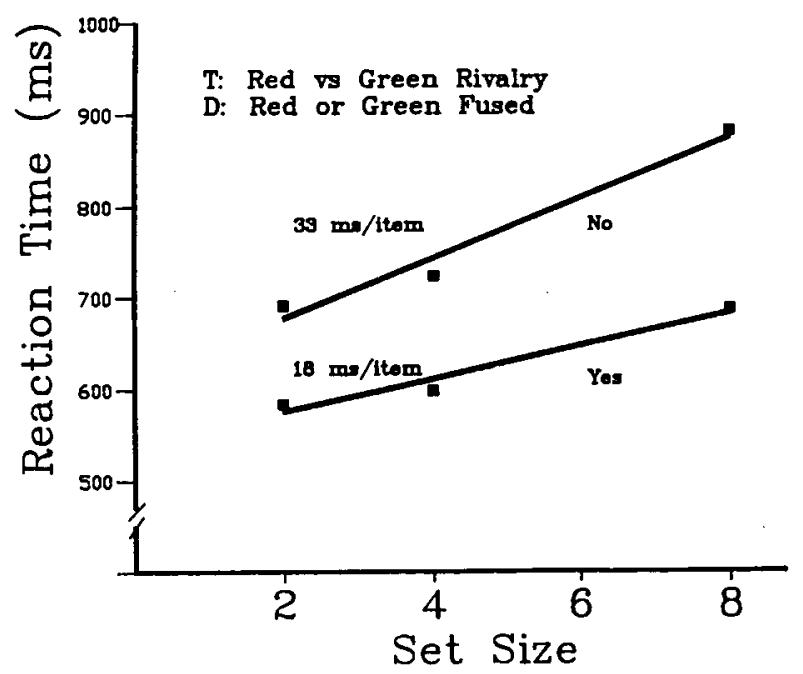

Figure 3. Searches for color rivalry targets among fused distractors. Average data for Experiment 2. Color rivalry targets do not pop out. searches for color-rivalry targets become slower as the set size increases.

Color rivalry is not the only possible outcome of dichoptic presentation of different colors. Sometimes the colors will fuse to produce a new hue (e.g., red and green could combine to produce a yellow, which is sometimes called "cortical yellow" because the color mixture could not occur prior to visual cortex) (Creed, 1935; deWeert \& Wade, 1987; Dunlap, 1944; Hering, 1920/1964, p. 250). There seem to be wide individual differences in binocular color mixture, with stimuli producing fusion for some subjects and rivalry for others. If color fusion had occurred for some subjects in this experiment, we might expect different results from those subjects. Specifically, a yellow target should be located in parallel in a field of red and green targets. We did not ask our subjects if they saw color fusion. However, none of our subjects showed a parallel pattem of results. It is possible that other pairs of color might produce good color fusion. We have not tested the possibility that dichoptically fused colors could be found in parallel.

\section{Experiment 4: Large Set Sizes}

\section{Method}

As noted above, there have been some reports that small and large set sizes can produce different results in visual search experiments (e.g., Pashler, 1987). In the present experiment, we repeated the form rivalry experiment (Experiment 1 ) with set sizes of 8, 16, and 32 items. The stimuli were left and right oblique rectangular-wave gratings of $4.2 \mathrm{cpd}$. Orthogonal gratings were presented dichoptically to produce the rivalry targets, while identical gratings were presented dichoptically as the fused distractors. As described in the General Methods section, these items are smaller $\left(0.85^{\circ}\right)$ and are not all equally distant from the fixation point. In all other details, the methods were identical to those in the previous experiments. Seven subjects were tested. There were 20 practice and 200 test trials per subject.

\section{Results}

As shown in Figure 4, the results of Experiment 4 support the hypothesis that rivalrous target items are not found in parallel. An ANOVA shows the main effects of set size and trial type to be highly significant $[F(2,12)=39.4$, $p<.001$, and $F(1,6)=39.4, p=.001$, respectively]. The interaction of set size and trial type is also significant $[F(2,12)=6.5, p<.012]$, indicating that the slope for target trials is different from that for negative trials. The average slopes, $9.5 \mathrm{msec}$ per item for target trials and $19.5 \mathrm{msec}$ per item for blank trials, are in the 2:1 ratio predicted by serial self-terminating search. All subjects had higher slopes for blank than for target trials. The hypothesis that the average slopes are the same is rejected $[t(6)=3.2, p<.025]$. As in Experiment 1, the 2:1 ratio hypothesis was tested. The target-trial slope was doubled and subtracted from the blank-trial slope for each subject. The resulting average difference $(0.6)$ does not differ significantly from zero $(t=0.12)$. The task is more difficult with the smaller stimuli. As a result, error rates were somewhat higher (averaging about 10\%). 


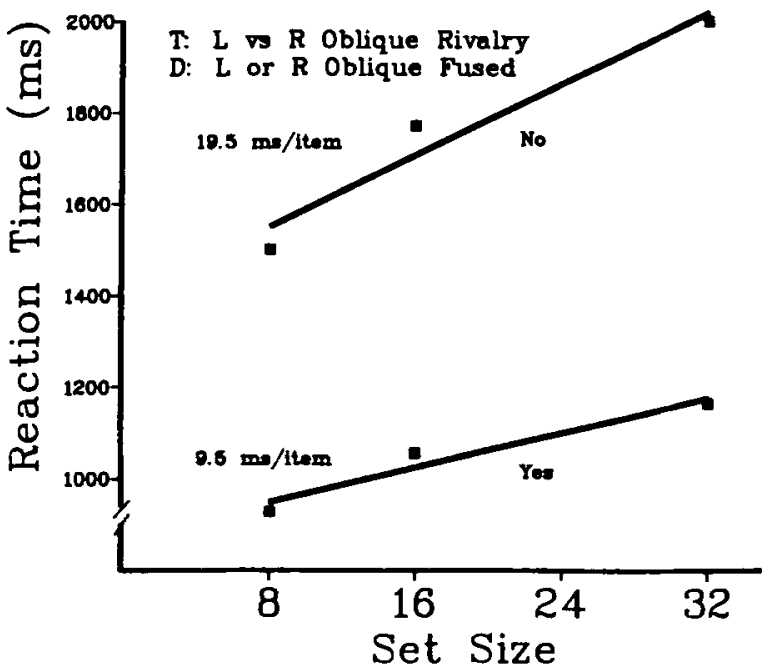

Figure 4. Searches for form rivalry targets with larger set sizes. RTs are consistent with serial search.

\section{Discussion}

The results of Experiment 4 are consistent with the predictions of a serial self-terminating search. In particular, the predicted 2:1 ratio of slopes is more reliable in this experiment than in the experiments with smaller set sizes. This mirrors the findings of Pashler (1987), using a different task.

The slopes in this experiment are somewhat shallower than those in the two previous experiments. The improved efficiency of serial search could be due to practice, or it may be that subjects could examine several of the smaller, more tightly packed items in one movement of an attentional "spotlight" (Pashler, 1987). With regard to the effects of practice, it is worth noting that the authors have run many thousands of trials of search for rivalry targets, including 1,600 trials on this specific task, without being able to produce parallel (slopes near zero) results.

\section{Experiment 5: Fused Targets}

Some visual search tasks are asymmetrical (Treisman \& Souther, 1985; Treisman \& Gormican, 1988). For example, slopes of RT versus set-size functions are shallower when subjects search for a tilted line among vertical distractors than when they search for a vertical line among tilted distractors (Treisman, 1986). Treisman has proposed that the presence of a stimulus attribute (e.g., "tilted") can pop out, whereas its absence may not. Perhaps the stimulus attribute in the preceding experiments is not "rivalry" but "fused." If so, visual search might be more independent of set size if subjects looked for a fused target among rivalry distractors.

\section{Method}

The methods were identical to those in Experiment 1, except that the target and distractor items were reversed. The two possible targets were vertical or horizontal lines presented to both eyes. The distractors were pairs of dichoptic orthogonal gratings that produced rivalry. Each of 7 subjects was tested for 30 practice and 300 test trials.

\section{Results}

The results, shown in Figure 5, were similar in form to those from the previous experiments. Average slopes were $31.5 \mathrm{msec}$ for target trials and $69.7 \mathrm{msec}$ for blank trials. The average slopes were steeper, although the differences in slopes between these results and those in Experiment 1 are not significant [two-sample $t$ test: target trials, difference of mean slopes $=5.3, t(17)=0.97$, not significant; blank trials, difference $=29.9, t=1.70$, almost, but not quite, significant]. Search appears to be serial. An ANOVA shows significant main effects of set size and trial type $[F(2,12)=22.3, p<.001$, and $F(1,6)$ $=43.12, p=.001$, respectively] and a significant set size $\times$ trial type interaction $[F(2,12)=6.032, p=.015]$. Slopes for target trials are significantly shallower than those for blank trials $[t=2.2, p<.05]$. Error rates were less than $5 \%$ for all subjects.

\section{Discussion}

Search is not parallel whether rivalry stimuli are the targets or the distractors. Although others have shown that stereoscopic depth pops out in visual search tasks (Nakayama \& Silverman, 1986), the results of this experiment suggest that simple zero-disparity fusion does not. There is an asymmetry between these results and those of Experiment 1 . That asymmetry, though statistically unreliable, supports the subjects' introspective reports that it is easier to search for the presence of rivalry than for its absence.

There could be an alternative account of the difficulty of the task in Experiment 5. In the search for a rivalry target, there was only one type of target: vertical versus horizontal rivalry. That rivalry could be produced by plac-

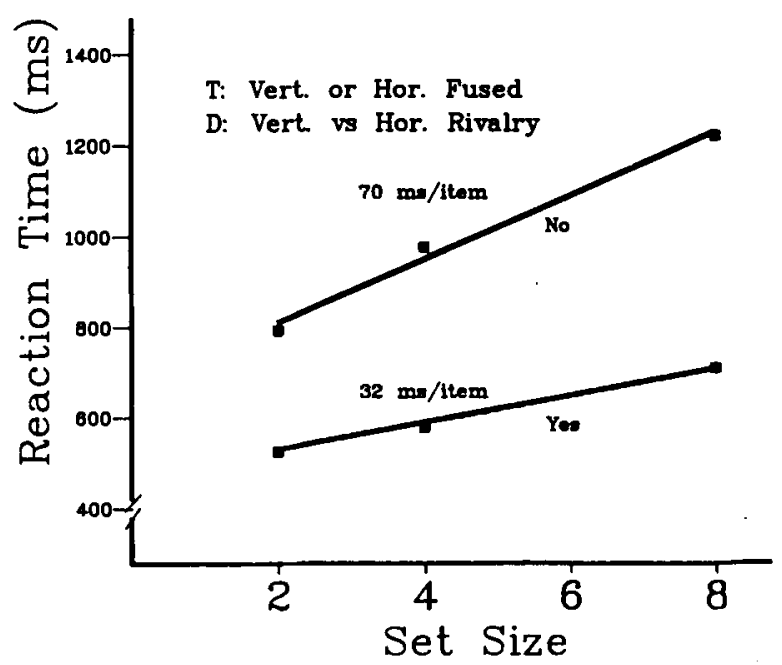

Figure 5. Searches for fused targets among rivalrous distractors. Average RTs show an increase with increasing set size. 
ing the vertical grating in the left or the right eye; the perceptual consequences were the same in either case. In the search for a fused target, there were two types of target: fused vertical or horizontal gratings. Perhaps the added burden of keeping track of both types slowed subjects' RTs. Even if this is true, it simply reinforces the conclusion that fusion does not act as a basic feature by itself. Subjects were not searching for fusion. They were searching for vertical or horizontal.

These results seem to fit well with the broad outlines of Julesz's and Treisman's views of parallel, preattentive visual processing. In general, the features that can be extracted in parallel during visual search are basic features of visual perception: orientation, color, depth, motion, and so forth. These are the attributes that naive observers might use to describe a visual stimulus. They seem selfevidently basic. Binocular rivalry, to the contrary, is not basic. It may be ubiquitous, but it is not particularly noticeable until one comes into the lab. It is, perhaps, not surprising that we have no special ability to detect its presence.

\section{Experiment 6: Binocular Luster}

There is an interesting exception to the claim that rivalry is not readily noticed, and that is the case of binocular luster. The simplest stimulus for luster is a dark field presented to one eye and a light field presented to the other (Helmholtz, 1909/1924, p. 512). Such a stimulus has a metallic sheen to it and looks quite different from other forms of rivalry. Convincing luster is produced when the stimulus in one eye is dimmer than the background while the stimulus to the other is brighter. Less convincing luster is seen when a bright spot is presented to one eye while the other eye sees no spot but only the background. Little or no luster is seen when both monocular spots are brighter than the background, even if they are of different brightnesses.

Binocular luster is an important component in the perception of the "shininess" of a surface (Tyler, 1983). If the set of features that supports parallel search is defined as a set of features that are important in the perception of surfaces, then luster may be a candidate feature, even if other types of rivalry are not.

\section{Method}

Experiment 6 was essentially the same as the color rivalry experiment (Experiment 3) with differences in the stimuli. There were two versions of Experiment 6, lustrous and nonlustrous. In the lustrous version, subjects viewed black and white $1.6^{\circ}$ spots on a gray background. Gray level was set by specifying the output of the TV guns on a scale from 0 to 255 . Here the background gray was 175 on the red, green, and blue guns. "Black" (actually a dark gray) was 100 on all guns, while white was 250 on all guns. To produce the lustrous target, a black spot was presented to one eye and a white one was presented to the other. The distractors were either black or white in both eyes. Thus, either eye alone saw a random collection of black and white spots. On target trials, both eyes together saw a variable number of black and white distractors and one lustrous target.
The nonlustrous version was identical to the lustrous version except that the background was reduced from 175 on all guns to 50 . This made both the 100 and 250 spots brighter than the background. Dichoptic presentation of the two spots appeared as a gray whose brightness was intermediate between the brightness of the dark 100 unit spot and the brighter 250 spot. Although it was a poor rivalry stimulus, the dichoptic mixture did appear somewhat unstable. It did not appear lustrous. These stimuli are illustrated in schematic form in Figure 6.

For both the luster and nonluster versions of the experiment, 7 subjects were tested in blocks of 30 practice and 300 test trials. Set sizes of 2, 4, and 8 elements were used. Targets were present on $75 \%$ of the trials. A replication of the luster version was run with targets present on $50 \%$ of the trials. Seven subjects were tested in the replication.

\section{Results}

Results for the lustrous and nonlustrous versions of Experiment 6 with $75 \%$ target trials are shown in Figures $7 \mathrm{a}$ and $7 \mathrm{~b}$. For the lustrous version, slopes are $4.9 \mathrm{msec} / \mathrm{item}$ for target trials and $4.1 \mathrm{msec} /$ item for blank trials. Error rates were under $3 \%$ for all subjects. ANOVA reveals significant main effects of set size and trial type $[F(2,12)$ $=15.3, p=.001$, and $F(1,6)=392.6, p<.001$, respectively]. The interaction was not significant $[F(2,12)$ $=0.112$ ]. Analyzed separately, the main effect of set size was significant for target trials $[F(2,12)=12.1, p=.001]$ but not for blank trials $[F(2,12)=3.8, p>.05]$.

By contrast, for the nonlustrous version of the same experiment, slopes are $37 \mathrm{msec}$ for target trials and $61 \mathrm{msec}$ for blank trials. Error rates for this more difficult task range from $1 \%$ to $15 \%$. Main effects of set size and trial type were significant $[F(2,12)=9.4, p<.01$, and $F(1,6)$ $=6.1, p<.05]$. The interaction was not significant $[F(2,12)=1.55, p>.05]$. The slopes for the nonlustrous version of this experiment are significantly steeper than for the lustrous version [two-sample $t$ tests: target

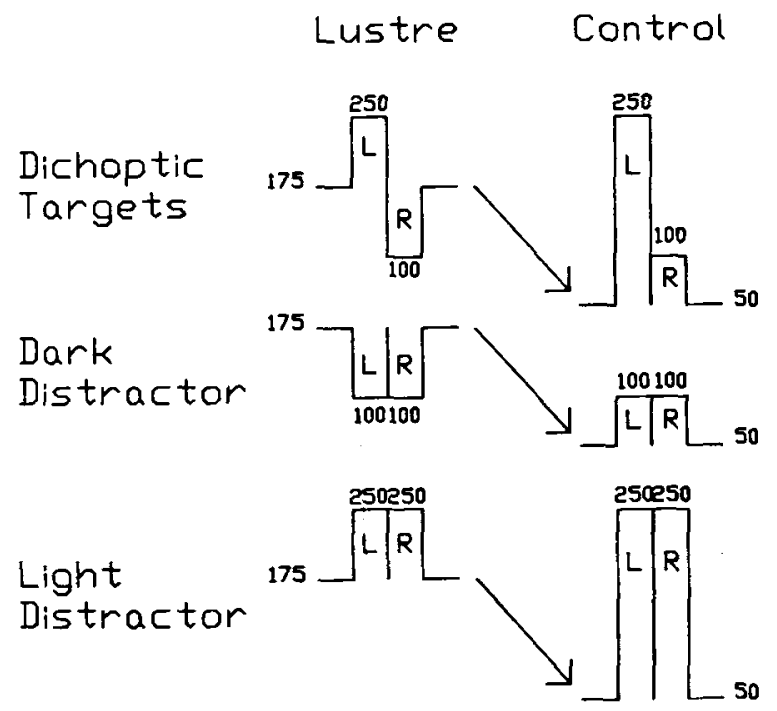

Figure 6. Stimuli for luster experiments. Luster is seen when the stimulus in one eye is brighter than the background while that in the other eye is darker. See text for details. 
(a)

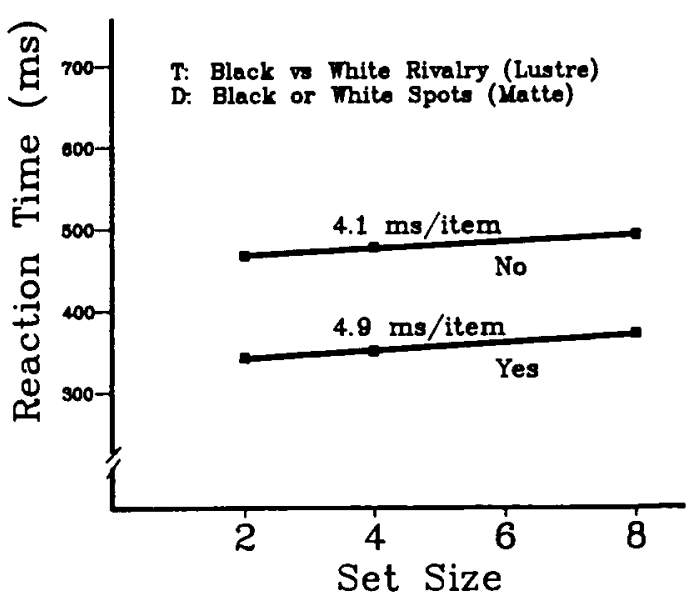

(b)

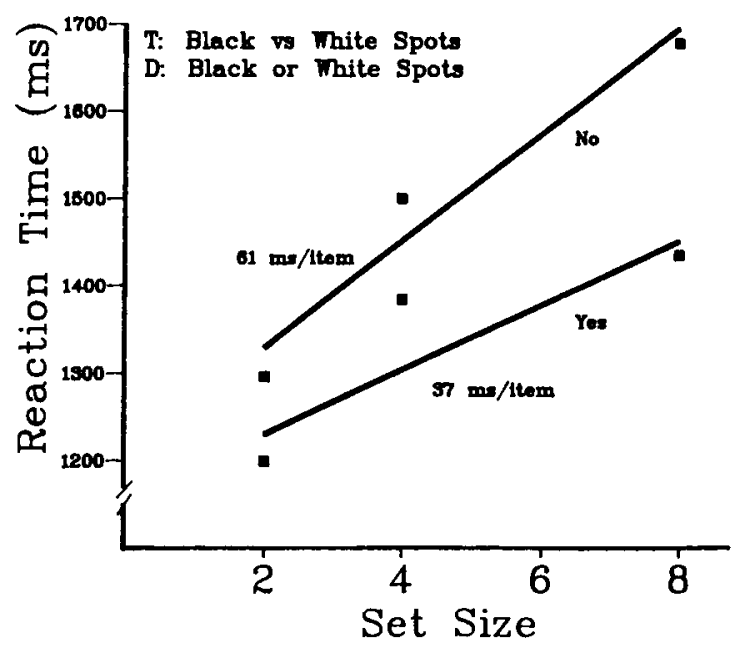

Figure 7. (a) Searches for lustrous targets among matte distractors. Average RTs are consistent with parallel search. (b) In searches for nonlustrous targets, RTs increase with increasing set size. See text and Figure 6 for stimulus details.

trials, $t(12)=3.2, p<.005$; blank trials, $t(12)=2.3$, $p<.025]$.

Results with $50 \%$ targets were similar. In the lustrous condition, average target trial slope was $2.0 \mathrm{msec} / \mathrm{item}$ (intercept $=423 \mathrm{msec}$ ). The average slope for blank trials was $8.0 \mathrm{msec}$ (intercept $=453 \mathrm{msec}$ ). Here the main effect of set size was not significant $[F(2,12)=3.8$, $p>.05]$. The main effect of trial type was significant $[F(1,6)=23.1, p<.01]$. The interaction was not significant $[F(2,12)=2.7, p>.05]$.

\section{Discussion}

Experiment 6 showed that targets defined by binocular luster can be found quite easily among nonlustrous distractors. In a case of true pop out, there should be no effect of set size for the target trials. Here there is a significant effect in the $75 \%$ target version of the experiment and no significant effect in the $50 \%$ version. The slopes of 4 and $2 \mathrm{msec} / \mathrm{item}$ are of about the same mag- nitude as the slopes for searches for such standard features as color and orientation (see, e.g., Treisman \& Gelade, 1980, Table 1). For purposes of this article, luster can be said to behave like color or form in supporting preattentive visual search.

In the nonlustrous control experiment, slopes are much steeper. This would seem to rule out the possibility that the performance in the luster condition is actually the result of parallel detection of one achromatic target from among two different achromatic targets. Introspection is clear on this matter. Search for luster resembles search for simple features because the shiny target pops out. When the same stimuli are presented in the nonlustrous version, the discrimination is based on fairly subtle differences in the apparent shade of gray of the target and distractors. This is more difficult and must be done in serial search.

\section{A Control Experiment: Spacing Effects}

\section{Method}

As in the rivalry detection experiments, stimulus spacing is confounded with set size. We examined the effects of spacing in a control experiment with methods drawn from Experiment 2 and stimuli drawn from Experiment 6 . Set size was held constant at 2 while the spacing of items was varied. On target trials, one item was lustrous and the other matte. On blank trials, both were matte. Four subjects were tested with 350 trials per subject.

\section{Results and Discussion}

Average RTs are shown in Table 2. As in Experiment 2, there was no effect of spacing $[F(6,18)=0.9$, $p=.5]$. Spacing does not seem to be a major influence on the results of these experiments.

\section{Experiment 7: Searching for Matte Targets (I)}

As noted above, Treisman found that some search tasks are asymmetric with the presence of an attribute being easier to detect than its absence. Since luster seems to be the "feature" in Experiment 6, we might expect to find that the absence of luster is not as easy to detect as its presence. In Experiment 7, subjects searched for a matte target among lustrous distractors.

Table 2

Average Response Times for Rivalry Search With a Set Size of 2 as Spacing Between the Two Items Varies

\begin{tabular}{ccc}
\hline & \multicolumn{2}{c}{ Average RT } \\
\cline { 2 - 3 } Spacing & Target Trials & Blank Trials \\
\hline 0 & 610 & 679 \\
1 & 653 & 682 \\
2 & 626 & 654 \\
3 & 608 & 609 \\
4 & 625 & 652 \\
5 & 604 & 628 \\
6 & 581 & 696 \\
\hline
\end{tabular}

Note-Spacing, the number of intervening blank positions, is defined as the clockwise spacing from target item to distractor item on target trials. For blank trials, spacings 0 and 6,1 and 5 , and 2 and 4 are identical. 


\section{Method}

The methods and stimuli were identical to those in the luster version of Experiment 6 . The only change was the transposition of target and distractors. Here subjects looked for a single black or white spot among binocularly lustrous distractors. Seven subjects were tested on blocks of 30 practice and 300 test trials. Targets were present on $75 \%$ of trials.

\section{Results}

The results are shown in Figure 8. The slope for target trials was $10.8 \mathrm{msec} / \mathrm{item}$. The slope for blank trials was $19.1 \mathrm{msec} /$ item. There was an unusually large degree of variation between subjects. As a result, the main effect of set size was marginally significant $[F(2,12)=3.72$, $p=.055]$. The effect of trial type was significant $[F(1,6)$ $=11.14, p=.016]$. The interaction was not significant $[F(2,12)=0.88, p=.44]$.

\section{Discussion}

Although these results suggest an asymmetry in the search for luster, it is not statistically significant. Indeed, the larger average slopes in Experiment 7 are almost entirely due to the strongly serial results for 1 subject (slopes of $39 \mathrm{msec} /$ item for target trials and $78 \mathrm{msec} / \mathrm{item}$ for blank trials). When that subject is removed from the average, the slopes become $6.0 \mathrm{msec} /$ item for target trials and $9.5 \mathrm{msec} /$ item for blank trials. ANOVA with this subject removed yields significant main effects of set size $[F(2,10)=23.0, p<.001]$ and trial type $[F(1,5)=$ $25.3, p=.004]$ but no significant interaction $[F(2,10)$ $=0.26, p=.77]$. There does not appear to be a strong asymmetry between searches for lustrous targets and search for matte targets.

In Experiment 6, there was one target (lustrous), although it could be made in either of two ways (left eye, white; right eye, black; or vice versa) and there were two distractors (white and black spots). In Experiment 7, there were two targets (black or white spots) and one distrac-

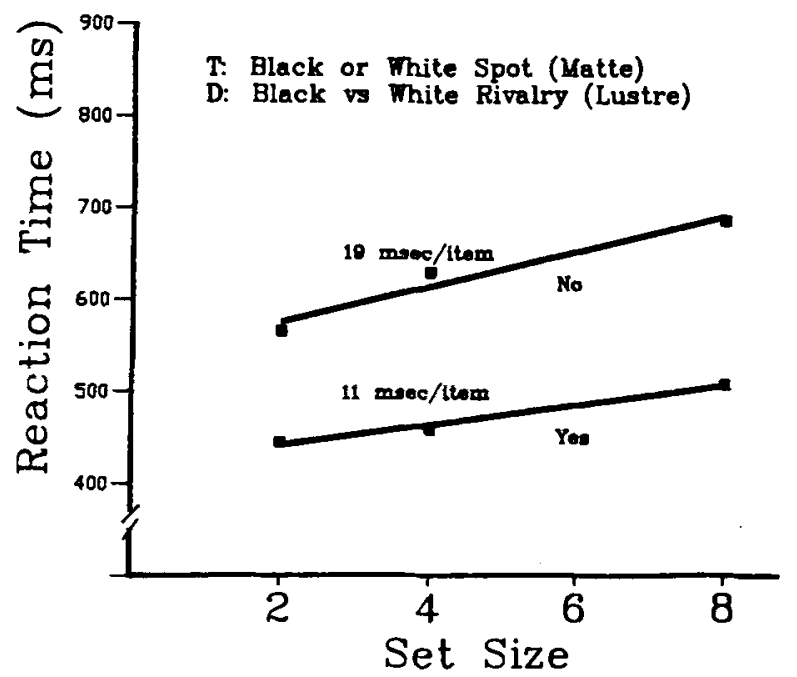

Figure 8. Searches for matte targets among lustrous distractors.
Table 3

Comparison of Results from Search for Lustrous Targets (Experiment 6) and Search for Matte Targets (Experiment 8), With Slopes (msec/item) Given for the Target Trial Condition

\begin{tabular}{lcccccccc}
\hline & & \multicolumn{6}{c}{ Subjects } \\
\cline { 3 - 9 } Target & Distractor & R.A. & A.R. & C.H. & A.F. & J.W. & S.F. & G.D. \\
\hline Luster & Matte & -3.4 & -2.6 & $\mathbf{0 . 2}$ & 1.3 & 5.0 & 5.7 & 7.8 \\
Matte & Luster & 15.9 & 14.1 & 8.8 & 6.0 & 0.8 & 3.5 & 5.2 \\
\hline
\end{tabular}

tor. In Experiment 8, we repeated Experiment 7 in a version with only one target.

\section{Experiment 8: Searching for Matte Targets (II)}

\section{Method}

In this version of the experiment, the target was always a binocular white spot. The distractors were the two versions of a lustrous spot (left eye, white; right eye, black; or vice versa). The experiment was run in two versions: with 75\% target trials and with 50\% target trials. Seven subjects were tested in each version. Twenty practice and 300 test trials were run for each subject.

\section{Results}

The average slopes for the $75 \%$ version were $5.1 \mathrm{msec} / \mathrm{item}$ for the target trials and $12.1 \mathrm{msec} / \mathrm{item}$ for the blank trials. The average slopes for the $50 \%$ version were $7.7 \mathrm{msec} / \mathrm{item}$ for the target trials and $8.0 \mathrm{msec} / \mathrm{item}$ for the blank trials. For both versions, the main effects of set size and trial type were significant but the interactions were not.

\section{Discussion}

On average, these slopes are somewhat steeper than those for the detection of a lustrous target, but there is no reliable evidence for an asymmetry. The weakness of the evidence for asymmetry becomes apparent if we look at the data from individual subjects. The same 7 subjects were tested in the $50 \%$ target trial versions of Experiments 6 and 8 , allowing us to look for asymmetries in individual data. The slopes for the target trials for these 7 subjects are shown in Table 3.

The slopes appear somewhat higher when subjects search for the matte target, but the difference is not significant (average difference $=5.8 \mathrm{msec} ; t=1.49$, $p>.05$; alternatively, Wilcoxon signed-ranks test, $p>.05)$. For 3 of 7 subjects, slopes are actually shallower in the matte search case. Most curiously, there is a strong negative correlation between a subject's slope in the luster search experiment and that subject's slope in the matte search experiment $(r=-0.88, r=-0.86$ if the calculation is done on ranks rather than on slopes). The cause of this negative correlation is unclear. Nevertheless, it is evidence against the hypothesis of a simple asymmetry, since such an asymmetry would produce a positive correlation.

The absence of a clear asymmetry between searches for matte and lustrous targets suggests that either of these sur- 
face properties can serve as a basic feature in visual search. Although significant main effects of set size were found in most of these searches, the shallow slopes for target trials are comparable to those reported for such basic features as color and orientation.

\section{Search for Rivalry: Cautionary Control}

We wish to describe one pitfall of this type of experiment. It is possible to be misled into thinking that some rivalry stimuli, other than those that produce luster, can be found in parallel search. For example, " \" presented to one eye and " / " presented to the other will produce rivalry, but they will also produce a somewhat unstable " $x$ " whose overall outlines are larger than either / or $\backslash$ alone. When subjects search for / versus \ rivalry among / or \ alone, the results are consistent with parallel search (very shallow slopes).

We can take the same stimuli and put them in a box. The / in one eye and $\backslash$ in the other will still produce rivalry, but rivalrous and nonfused stimuli will have the same overall outlines. In this case, the results are not consistent with parallel search (steeper slopes), suggesting that the shallow slopes in the previous experiment are due to the parallel detection of the difference in outline of the rivalrous and fused items and not to parallel detection of rivalry. The property that can be found in parallel is "shape," and that has nothing to do with the binocularity of the stimulus.

\section{Rivalry Searches: General Discussion}

Part 1 of this paper can be summarized simply. Binocular rivalry can be used to define items in a visual search paradigm. Searches based on rivalry are serial except in the case of binocular luster. Lustrous targets support parallel visual search, making luster a candidate "basic feature" or "texton."

\section{PART 2: \\ UTROCULAR SEARCHES}

In this section, we present the results of two experiments in which the targets are defined by eye-of-origin of "utrocular" information (Black \& Cormack, 1979; Enoch, Goldman, \& Sunga, 1969; Smith, 1945). These are visual search tasks that can be performed only with knowledge of which eye is receiving which stimulus. Such searches are of interest because they can provide information about the locus of visual search. For example, if the mechanism for visual search lay in the monocular parts of the visual pathway, it might be possible to do searches based on purely monocular information. However, as the results of the following experiments will show, these utrocular searches are virtually impossible, suggesting that visual search occurs after eye-of-origin information is irrevocably lost.

\section{Experiment 9: Simple Utrocular Detection}

\section{Method}

In this experiment, the target was a monocular white spot on a dark background presented to one eye. The distractors were identical white spots presented to the other eye. Obviously, this is a trivial task if one eye is closed. For many subjects, there are slight, but reliable, differences in apparent brightness between the eyes. This cue can be used to perform visual searches of this sort, but the task is then not a utrocular task but a brightness-discrimination task. To eliminate this confounding cue, both target and distractor spots could take any of four brightness values. As in all of these experiments, feedback was provided after each trial. This is of particular importance in this case because utrocular discrimination appears to be possible only with feedback (Ono \& Barbeito, 1985).

Five subjects were tested on 300 trials each. Targets were presented on $50 \%$ of the trials. Set sizes were 2,4 , and 8 items. The target was always presented to the same eye. Target eye was varied between subjects.

\section{Results}

Even though the task would be trivial with one eye closed, it is not trivial with both eyes open. For each subject, the results for each set size form a $2 \times 2$ matrix of hits, false alarms, true negatives, and misses. A chi-square test can be used to determine if the distribution of responses into these four bins differs significantly from chance. For 4 of the 5 subjects chi-square values failed to meet the 5\% significance level for any set size. For 1 subject, the 2-element set size yielded a significant chisquare. Four- and 8-element sets were not significant. Given that the subjects were responding randomly, the RT data for this experiment are of little interest.

\section{Discussion}

To the subject, this is an impossible (and frustrating) task. It is, of course, difficult to prove that a task is impossible. At the very least, this task is clearly very different from other tasks in which error rates are around $5 \%$. Certainly, there is no evidence from these data that the subjects can do the task. Some utrocular tasks are possible (e.g., Blake \& Cormack, 1979). Generally, these rely on a somewhat mysterious, visceral 'feeling' in the eye whose origins are not well understood (Martens, Blake, Sloane, \& Cormack, 1981). Ono and his colleagues have shown that the feeling is useful only with feedback and is otherwise ambiguous (Ono \& Barbeito, 1985). The feeling seems to arise in the eye that is deprived of stimulation. In the present task, depriving one eye of one of several spots does not seem to give rise to this feeling and so, even with feedback, the subjects respond randomly.

Monocular information is preserved at least into early visual cortical processing. The results of Experiment 9 suggest that the mechanisms of visual search do not have access to that monocular information. Experiment 10 confirms this hypothesis with a different type of utrocular task. 


\section{Experiment 10: A Utrocular Rivalry Task}

\section{Method}

In this experiment, the monocular stimuli are the same vertical and horizontal gratings that were used in Experiment 1. Here one eye is presented with distractors of one orientation and a target of the orthogonal orientation. The other eye is presented with the orthogonal orientation at each stimulus location. Thus both eyes see vertical versus horizontal rivalry at all locations. For example, on one trial, the left eye might see vertical distractors at seven locations and a horizontal target at the eighth. Under simple binocular viewing conditions, a target of one orientation would pop out from among distractors of another orientation. The right eye would see horizontal distractors at the same seven locations and a vertical target at the eighth location. Since rivalry is a local phenomenon, this will produce independent instances of vertical versus horizontal rivalry at all eight locations. Nevertheless, if visual search has access to information present prior to the locus of rivalry, then the task should be simple and parallel, because the information required for parallel search is available in each monocular input.

As in Experiment 9, brightness of the monocular gratings was varied in order to eliminate cues due to differences in apparent brightness between the two eyes. Eight subjects were tested for 300 trials each. Targets were present on $50 \%$ of the trials, and set sizes of 2,4 , and 8 were used.

\section{Results}

The results were similar to those of Experiment 9. The task seemed virtually impossible. Chi-square values failed to reach significance at any set size for 7 of the 8 subjects. The 8th subject had significant chi-square values for set sizes of 2 and 4 but not for the set size of 8 . As in the previous experiment, the lack of evidence of any ability to do the task renders the RT data uninteresting.

\section{Discussion}

Finding one orientation among distractors of another is a simple search task. Information for such a search is available in the visual pathway from the locus at which orientation information is extracted to the locus of binocular rivalry. At the locus of rivalry, the orientation information is lost. The psychophysical locus of rivalry is the subject of some dispute (see, e.g., Blake \& Boothroyd, 1985; Blake \& O'Shea, 1988; Wolfe, 1986, 1988) and the neurophysiological locus is even less clearly known (e.g., Wolfe \& Blake, 1985). Nevertheless, rivalry is known to occur fairly late in early visual processing, after the first analysis of basic visual features such as orientation, size, color, and motion (see Blake \& Overton, 1979; Wolfe, 1986; or Wolfe \& Blake, 1985, for reviews of this evidence). Apparently, the mechanisms of visual search are "higher" in the visual pathway than the locus of rivalry. At least, the results of Experiment 10 indicate that information that is available only prior to that locus is not available to visual search. The experiments on visual search for rivalry stimuli show that both parallel and serial search are possible for one class of stimulus information that is available only after the locus of rivalry. Experiment 11 shows that a second class of such stimuli can also support visual search.

\section{CYCLOPEAN SEARCHES}

\section{Experiment 11: Searching for Cyclopean (But Nonstereoscopic) Stimuli}

Cyclopean stimuli are stimuli that are seen only by both eyes acting together and not by either eye acting alone. Stereoscopic depth is the premier example of a cyclopean stimulus, but it is not the only example (e.g., Wolfe \& Held, 1979). As noted earlier, stereoscopic depth is a feature that can be found in parallel visual search. In Experiment 11 , we show that a nonstereoscopic cyclopean stimulus can also support parallel search.

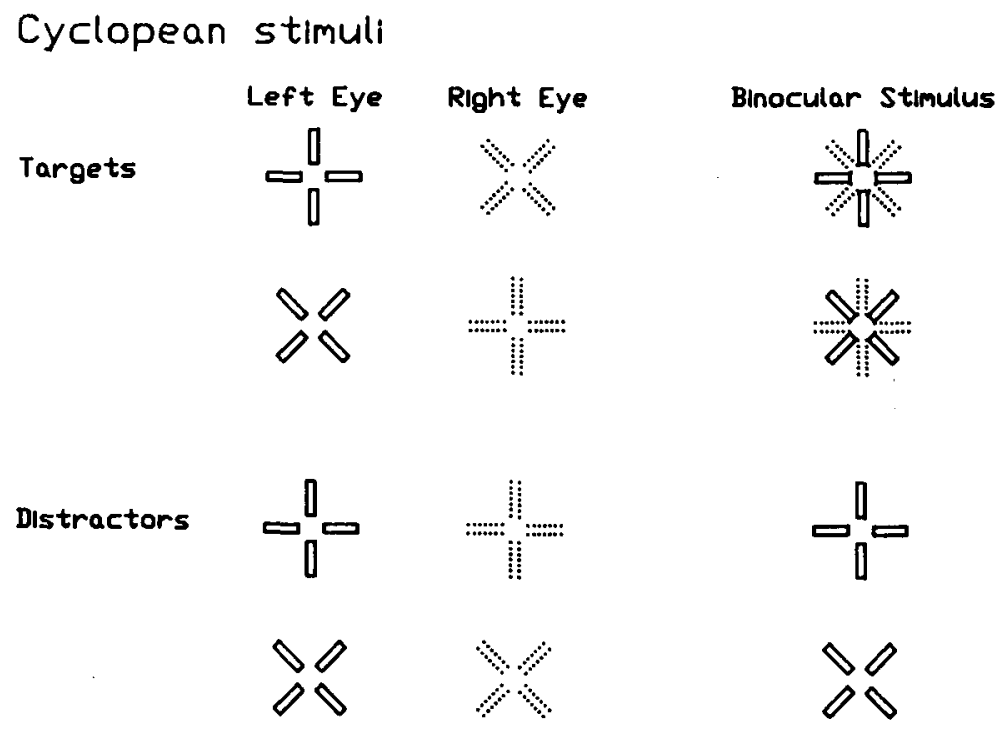

Figure 9. Cyclopean stimuli are stimuli that can be seen only binocularly. Here the target $*$ is cyclopean. Each monocular view consists of an assortment of $x$ and + . Cyclopean stimuli need not (and here do not) involve stereopsis. 


\section{Method}

The stimuli for Experiment 11 are shown in Figure 9. All of the monocular stimuli are $+s$ or $\times s$. The target was a + presented to one eye and $x$ to the other. The holes in the center of the figures prevented the dichoptic combination of + and $x$ from producing rivalry. Instead, the dichoptic combination yielded an 8-armed $*$. The distractors were binocular $+s$ and $\times s$. A target $*$ with 8 elements should be found in parallel in a field of 4-element + and $x$ distractors. In this case, the 8-element target is available only binocularly. No information about its presence can be obtained from either monocular input alone. It is important to note that the cyclopean information in these stimuli is only in the form of the target ( + or $\times$ vs. *). None of the stimuli in this experiment give rise to a sensation of stereoscopic depth.

Seven subjects were tested on 300 trials per subject. Targets were present on $75 \%$ of the trials. Set sizes of 2,4 , and 8 were used. As a control, each of 8 subjects was tested for 300 trials with binocular $*$ targets and binocular + and $x$ distractors. Here information sufficient to find the target is available in the monocular inputs. Otherwise, the two versions of the experiment are identical.

\section{Results}

Figures $10 \mathrm{a}$ and $10 \mathrm{~b}$ give the results for the Experiment 11 and its control. In both cases, the task was easy and the search was parallel. The slopes for the target trials were $1.1 \mathrm{msec} / \mathrm{item}$ for the experimental group and $1.8 \mathrm{msec}$ for the control. Error rates were less than 5\% for all but 1 subject in each version. That subject had error rates of about $10 \%$. The slopes for blank trials are significantly steeper. In the control condition, the slope is $9.0 \mathrm{msec} / \mathrm{item}$. In the cyclopean condition, it is $30 \mathrm{msec} /$ item. The difference between these two average slopes is due entirely to 1 subject with a very high slope for blank trials in the cyclopean condition (118 msec/item!). Without that subject, the average slope for blank trials is $14.1 \mathrm{msec}$, similar to the $9.0-\mathrm{msec} / \mathrm{item}$ slopes obtained in the control condition.

For the cyclopean condition, the main effect of set size is not significant $[F(2,12)=3.5, p=.63]$, the effect of trial type is significant $[F(1,6)=28.1, p=.002]$, and the interaction is not significant $[F(2,12)=3.4, p=.6]$. For the binocular control condition, the effect of set size is significant $[F(2,14)=13.8, p<.001]$. When analyzed separately, the effect of set size is significant for blank trials $[F(2,14)=11.2, p=.001]$ but not for target trials $[F(2,14)=0.9, p=.42]$. The effect of trial type was significant $[F(1,7)=264.6, p<.001]$. The interaction of set size and trial type was not significant $[F(2,14)=$ $3.6, p>.5]$.

\section{Discussion}

The cyclopean and binocular versions of this task produce similar results. The target * pops out and is easily found, even when it is present only in cyclopean vision. Although this may not be surprising, Experiment 11 provides useful information. Parallel visual search is possible for stimuli that, in a real sense, do not exist prior to the combination of inputs from the two eyes even when the combination of those monocular inputs does not give rise to a new stimulus attribute such as stereoscopic depth (Nakayama \& Silverman, 1986) or binocular luster (Ex- (a)

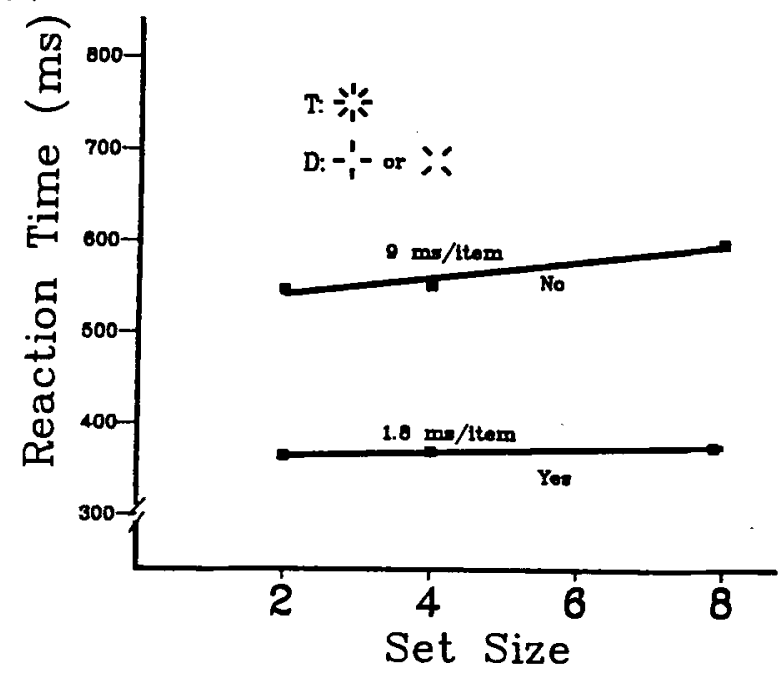

(b)

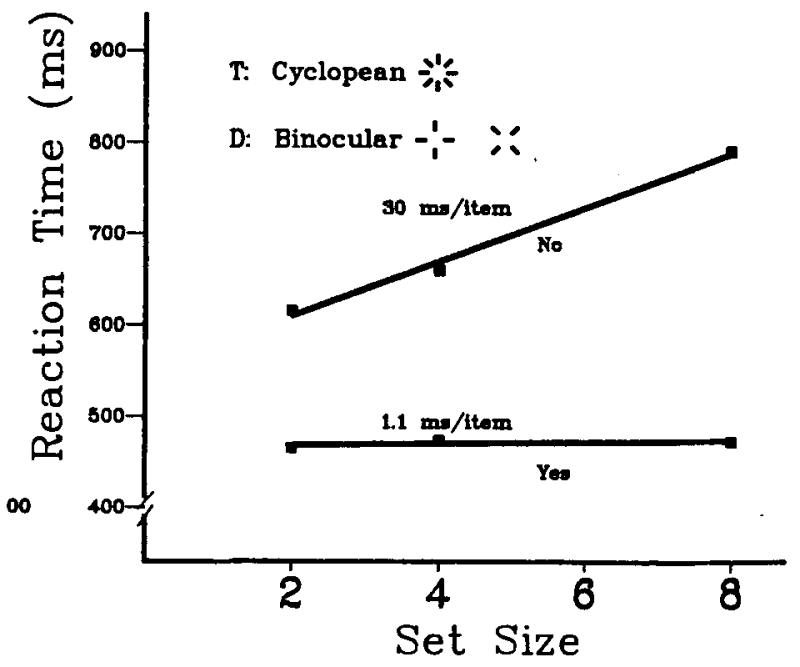

Figure 10. (a) Searches for a cyclopean * . Average RTs on target (yes) trials are consistent with parallel search. The relatively steep slope for blank (no) trials reflect the extremely steep slope for 1 subject. (b) Searches for monocularty visible * . RTs are consistent with parallel search.

periment 6). The utrocular experiments indicated that visual search could not be done on the basis of information available only prior to binocular combination. Taken together, these results argue that the mechanisms of visual search lie after binocular interactions such as rivalry and stereopsis in the sequence of visual processing.

For some blank trials, subjects appear to conduct a serial check to assure themselves that a target is not present. This would account for the steeper slopes for the blank trials in these experiments.

\section{GENERAL DISCUSSION AND CONCLUSIONS}

The results of these experiments can be summarized in three main points. (1) Searches based on detection of binocular rivalry are possible but are not independent of 
set size, except when the rivalry gives rise to binocular luster. Luster behaves like a basic feature in visual search perhaps because luster is an important property in the description of the appearance of surfaces and the other manifestations of rivalry are not. (2) Searches requiring information about the eye of origin of a stimulus are not possible, suggesting that visual search mechanisms do not have access to parts of the visual system where such information is available. (3) Searches for cyclopean stimuli are parallel when the binocular combination gives rise to a feature like shape or size.

The finding that binocular luster can pop out might cause us to reexamine the rest of the list of basic features or textons. Why do some stimulus attributes support preattentive parallel visual search, while others do not? Many workers (e.g., Julesz, 1984) have noted a similarity between the list of textons and the list of basic visual properties extracted in early visual processing (e.g., color, orientation, size, etc.). Julesz (1984) points out that the match is not perfect. Intersections can behave as textons but have not been described as particularly potent trigger features for cells in striate or extrastriate cortex. Luster falls into the same category. It is possible that the physiological data simply have not been collected. It is also possible that the two lists, textons and basic visual properties, are similar but not identical. Perhaps the texton list is the list of the basic perceptual properties of visible surfaces. This list would include basic visual properties, such as color and size, but also more complex features, such as luster (or shininess) and the junction and intersection features that allow us to parse the visual scene into objects (see Waltz, 1975). By contrast, the list of the basic visual properties extracted in the first stages of visual processing would include items such as color and size that are found on the texton list, but might also include rivalry and eye-of-origin information that are not on the texton list.

\section{REFERENCES}

BLAKE, R., \& BOOTHROYD, K. (1985). The precedence of binocular fusion over binocular rivalry. Perception \& Psychophysics, 37, 114-124.

Blake, R., \& CoRmack, R. H. (1979). On utrocular discrimination. Perception \& Psychophysics, 26, 53-68.

Blake, R., \& O'ShEa, R. P. (1988). "Abnormal fusion" of stereopsis and binocular rivalry. Psychological Review, 95, 151-154.

Blake, R., \& Overton, R. (1979). The site of binocular rivalry suppression. Perception, 8, 143-152.

BLAKE, R., WESTENDORF, D. H., \& OVERTON, R. (1980). What is suppressed during binocular rivalry? Perception, 9, 223-231.

Breese, B. B. (1909). Binocular rivalry. Psychological Review, 16, 410-415.

CREeD, R. S. (1935). Observations on binocular fusion and rivalry. Journal of Physiology, 84, 381-392.

DEWEERT, C. M. M., \& WADE, N. J. (1987). Novel stimuli for dichoptic colour mixing. Manuscript submitted for publication.

DunLAP, K. (1944). Alleged binocular color mixing. American Journal of Psychology, 57, 559-563.

Egeth, H. E., Virzi, R. A., \& Garbart, H. (1984). Searching for conjunctively defined targets. Journal of Experimental Psychology: Perception \& Performance, 10, 32-39.
Enoch, J., Goldman, H., \& SUnga, R. (1969). The ability to distinguish which eye was stimulated by light. Investigative Ophthalmology, 8, 317-331.

Hastorf, A. H., \& MYro, G. (1959). The effect of meaning on binocular rivalry. American Journal of Psychology, 72, 393-400.

HeLMHOLTZ, H. vON. (1924). Treatise on physiological optics (J. P. C. Southall, Trans.). New York: The Optical Society of America. (Original work published 1909)

HerING, E. (1964). Outlines of a theory of the light sense (L. Hurvich \& D. Jameson, Trans.). Cambridge, MA: Harvard University Press. (Original work published 1920)

Johnston, W. A., \& DARK, V. J. (1986). Selective attention. Annual Review of Psychology, 37, 43-76.

JuLESZ, B. (1981). A theory of preattentive texture discrimination based on first order statistics of textons. Biological Cybemetics, 41, 131-138.

JulEsz, B. (1984, February). A brief outline of the texton theory of human vision. Trends in Neuroscience, 7, 41-45.

JuLESZ, B. (1986). Texton gradients: The texton theory revisited. Biological Cybernetics, 54, 245-251.

Julesz, B., \& Bergen, J. R. (1983). Textons, the fundamental elements in preattentive vision and perceptions of textures. Bell System Technical Journal, 62, 1619-1646.

KAUFMAN, L. (1963). On the spread of suppression and binocular rivalry. Vision Research, 3, 401-415.

Martens, W., Blake, R., Sloane, M., Cormack, R. H. (1981). What masks utrocular discrimination? Perception \& Psychophysics, 30, 521-532.

Nakayama, K., \&ilverman, G. H. (1986). Serial and parallel processing of visual feature conjunctions. Nature, 320, 264-265.

ONo, H., \& BarbeITo, R. (1985). Utrocular discrimination is not sufficient for utrocular identification. Vision Research, 25, 289-299.

PAshler, H. (1987). Detecting conjunctions of color and form: Reassessing the serial search hypothesis. Perception \& Psychophysics, 41, 191-201.

SMITH, S. (1945). Utrocular or 'which eye' discrimination. Journal of Experimental Psychology, 35, 1-14.

Steinman, S. (1987). Serial and parallel processing of the cues to hyperacuity. Investigative Ophthalmology \& Visual Science, 28(Suppl.), 361.

STERNBERG, S. (1969). High-speed scanning in human memory. Science, $153,652-654$.

Townsend, J. T. (1971). A note on the identification of parallel and serial processes. Perception \& Psychophysics, 10, 161-163.

TownsEND, J. T. (1976). Serial and within-stage independent parallel model equivalence on the minimum completion time. Journal of Mathematical Psychology, 14, 219-239.

Treisman, A. (1986). Features and objects in visual processing. Scientific American, 255, 114B-125.

Treisman, A., \& Gelade, G. (1980). A feature-integration theory of attention. Cognitive Psychology, 12, 97-136.

Treisman, A., Gormican, S. (1988). Feature analysis in early vision: Evidence from search asymmetries. Psychological Review, 95 , 15-48.

Treisman, A. M., \& SCHMidt, H. (1982). Ilusory conjunctions in the perception of objects. Cognitive Psychology, 14, 107-141.

Treisman, A., Souther, J. (1985). Search asymmetry: A diagnostic for preattentive processing of separable features. Journal of $E x-$ perimental Psychology: General, 114, 285-310.

TYLER, C. W. (1983). Sensory processing of binocular disparity. In C. Schor \& K. Ciuffreda (Eds.), Vergence eye movements: Basic and clinical aspects (pp. 199-295). Boston: Butterworth.

WALKer, P. (1978). Binocular rivalry: Central or peripheral selective processes. Psychological Bulletin, 85, 376-389.

WALTZ, D. (1975). Understanding line drawings of scenes with shadows. In P. H. Winston (Ed.), The psychology of computer vision. New York: McGraw-Hill.

WoLfe, J. M. (1986). Stereopsis and binocular rivalry. Psychological Review, 93, 269-282.

Wolfe, J. M. (1988). Parallel ideas about stereopsis and binocular rivalry. Psychological Review, 95, 155-158. 
WOLFE, S. M., \& BLAKE, R. (1985). Dissecting the binocular visual system with psychophysical tools. In D. Rose \& V. G. Dobson (Eds.), Models of visual cortex (pp. 192-199). New York: Wiley.

Wolfe, J. M., \& HeLD, R. (1979). Eye torsion and visual tilt are mediated by different binocular processes. Vision Research, 19, 917-920.

Wolfe, J. M., Cave, K. R., \& Franzel, S. L. (1988). A modified feature integration model for visual search. Manuscript submitted for publication.

\section{NOTE}

1. The use of equivocal terms such as "appears to be ... parallel" in the preceding paragraph is deliberate. Townsend $(1971,1976)$ has shown that the distinction, on the basis of RT data, between serial processes and parallel processes is not as clear as once thought (e.g., Sternberg, 1969). In particular, limited-capacity parallel processes can yield RTs that increase linearly with set size. Nevertheless, there does appear to be an important distinction between searches that can be completed with great ease, independent of the number of items and those that require more effort and introspectively appear to require serial examination of multiple loci before the target item is found. We will use the terms "serial" and "parallel" cautiously in the manner that they are used in Treisman's work. Operationally, the terms are defined relative to the slopes of RT $\times$ set-size functions.

(Manuscript received June 25, 1987;

revision accepted for publication December $28,1987$. )

\section{Notice}

\section{New Editor of Animal Learning \& Behavior}

Vincent M. LoLordo will assume the editorship of Animal Leaming \& Behavior in 1989. After July 1, 1988, manuscripts submitted to Animal Learning \& Behavior should be sent to him at the Department of Psychology, Dalhousie University, Halifax, Nova Scotia B3H 4J1, Canada. 